\title{
MELHORAMENTO DO TRIGO: XXI. AVALIAÇÃO DE LINHAGENS EM DIFERENTES REGIÕES PAULISTAS $\left({ }^{1}\right)$
}

\author{
CARLOS EDUARDO DE OLIVEIRA CAMARGO $(2,6)$, JOÃO CARLOS FELICIO $(2,6)$, \\ ANTONIO WILSON PENTEADO FERREIRA FILHO (2), JOSÉ GUILHERME \\ DE FREITAS $(2,6)$, BENEDITO DE CAMARGO BARROS $(3,6)$, JAIRO LOPES \\ DE CASTRO $(4,6)$, JOSÉ CARLOS SABINO $(5,6)$ \\ Q LAÉRCIO SOARES ROCHA JUNIOR (2)
}

\begin{abstract}
RESUMO
Foram comparadas entre si vinte e três linhagens e dois cultivares comerciais de trigo através de ensaios instalados em diferentes regiōes paulistas, em 1984/86, analisando-se a produtividade, características agronômicas, resistência às doenças e tolerância ao alumínio. Considerando os ensaios conduzidos em Capão Bonito, a linhagem 19 destacou-se quanto à produção de grãos, como moderadamente resistente à helmintosporiose, muito tolerante à toxicidade de $\mathrm{Al}^{3+}$, ciclo precoce e, apesar do porte alto, boa resistência ao acamamento. Nos ensaios do Vale do Paranapanema (Cruzália e Cândido Mota), sobressaíram o cultivar BH-1146 e a linhagem 16
\end{abstract}

(1) Trabaiho apresentado na XV Reuniâo Nacional de Pesquisa de Trigo, Passo Fundo (RS), 1988. Com verba supiementar do Acordo do Trigo entre as Cooperativas de Produtores Rurais do Vale do Paranapanema e a Secretaria de Agricultura e Abastecimento/instituto Agronômicc. Recebido para publicaçāo em 9 de agosto de 1988 e aceito em 13 de fevereiro de 1989.

(2) Seçãode Arroze Cereais delnverno, InstitutoAgronômico(IAC), CaixaPostal28, 13001Campinas, SP.

(3) Seção de Doenças das Plantas Alimentícias Básicas e Olerícolas, Instituto Biológico (IB), Caixa Postal 70, 13093 Campinas, SP.

(4) Estação Experimental de Capão Bonito, IAC.

(5) Estação Experimental de Tietê, IAC.

(6) Com boisa de pesquisa do CNPq. 
quanto à produção de grãos. A linhagem 16 apresentou porte baixo, ciclo precoce, resistência de campo à ferrugem-da-folha, resistência ao acamamento e tolerância ao $\mathrm{Al}^{3+} \mathrm{e}$, em Tietê, foi a mais produtiva. No ensaio de Campinas, não foram detectadas diferenças entre os tratamentos quanto à produção de grãos. As linhagens $1,3,9,10,11,15,16,22$ e 23 e o cultivar Alondra-S-46 mostraram plantas de porte semi-anão, diferindo significativamente do 'BH-1146', de porte alto. Em relação à ferrugem-do-colmo (Puccinia graminis f. sp. tritici), as linhagens 9, 10 e 11 e o 'Alondra-S-46' foram resistentes às seis raças testadas em estádio de plântula em casa de vegetação. Em condição de infecção natural no estádio de planta adulta, as linhagens 11, 16 e 18 e o 'BH-1146' apresentaram menor grau de infecção de ferrugem-da-folha $(P$. recondita). A linhagem 7 , com espigas compridas, 7 e 8 , com maior número de espiguetas por espiga, 2, com grande fertilidade nas espigas, e 21, com grãos mais pesados, representaram boas fontes genéticas dessas características ao programa de melhoramento. As linhagens $1,3,5,12,13,14,16,17,18,19$ e 21 e o cultivar $\mathrm{BH}-1146$ foram tolerantes à presença de $10 \mathrm{mg}$ de $\mathrm{Al}^{3+} /$ itro em solução nutritiva.

Termos de indexação: melhoramento genético vegetal; trigo; produçăo de grāos; ferrugem-do-colmo; ferrugem-da-folha; toxicidade de aluminio.

\section{INTRODUÇÃO}

Para o Estado de São Paulo, os trabalhos de obtenção de novos cultivares de trigo devem considerar os seguintes aspectos: maior produtividade, porte semi-anão, palha forte (resistência ao acamamento), maior fertilidade da espiga, maior perfilhamento, precocidade (ciclo da emergência à maturação de 100 a 120 dias para favorecer a rotação com outras culturas), resistência à degrana, resposta à adubação, indice de colheita mais alto (relação entre o peso dos grãos e o peso total da parte aérea da planta), adaptação ampla, resistência às doenças (ferrugens, oídio e helmintosporiose), tolerância à toxicidade de alumínio, manganês e ferro, eficiência à absorção e utilização de fósforo e nitrogênio e melhores qualidades nutritivas e tecnológicas. Obtido o cultivar, faz-se necessário um programa eficiente de multiplicação de sementes visando à agilização do fornecimento do novo material genético aos agricultores (CAMARGO, 1987).

Trabalhos desenvolvidos pelo Instituto Agronômico permitiram o lançamento de cultivares com sigla IAC (IAC-1 a IAC-11), no final da década de $60 \mathrm{e}$ início da de 70, dos quais o IAC-5 foi o de maior importância para o Brasil, pois, no final da década de 70 e início dos anos oitentas, foi o mais plantado nas regiōes triticolas nacionais (ALCOVER, 1969, 1971; CAMARGO, 1972). Atualmente, sua utilização vem caindo, principalmente devido ao surgimento de novos cultivares mais produtivos e resistentes aos patógenos causadores das doenças. 
Trabaihos desenvolvidos na década de 70 possibilitaram o plantio de variedades de origem mexicana, de porte baixo, resistentes aos patógenos causadores das ferrugens-do-colmo e da-folha em solos de alta fertilidade sem ocorrência de toxicidade de $\mathrm{Al}^{3+}$ (CAMARGO, 1972; CAMARGO et al., 1974; FELÍCIO et al., 1976). Entre elas, pode-se citar. ISWRN 526-63, Sonora-63, ISWRN 152-63, LA-1434 e Pitic-62. Posteriormente, os cultivares mexicanos Tobari-66, INIA-66, Jupateco-73 e Alondra-4546 foram recomendados aos agricultores. Atualmente, o cultivar mexicano Anahuac representa a maior área de plantio de sequeiro e irrigado paulista em solos sem a presença de $\mathrm{Al}^{3+}$.

No final da década de setenta e nos anos oitentas, novos cultivares de trigo foram lançados para o Estado de São Paulo, provenientes de um trabalho conjunto dos diferentes Institutos de Pesquisa da Coordenadoria da Pesquisa Agropecuária. Esse trabalho permitiu o lançamento dos cultivares IAC-13, IAC-17, IAC-18, IAC-21, IAC-22, IAC-23, IAC-24, IAC-25, IAC-27, IAC-28, IAC-60, IAC-74, IAC-161 e IAC-162, com base em ensaios de competição de cultivares plantados nas diferentes regiōes tritícolas, em solos com e sem alumínio (FELíCIO et al., 1983, 1985; SĀO PAULO, 1985, 1986).

$O$ presente trabalho teve por objetivo avaliar 23 linhagens de trigo, recém-obtidas no programa de melhoramento genético, e dois cultivares atualmente em cultivo, quanto à produção de grãos, características agronômicas, resistência às doenças e tolerância à toxicidade de $\mathrm{Al} 3+$, visando à escolha das mais promissoras para multiplicação e posterior lançamento aos triticultores, ou reutilizá-las no programa de cruzamentos para corrigir possiveis defeitos.

\section{MATERIAL E.MÉTODOS}

\subsection{Origem das linhagens e cultivares estudados}

Linhagem 1: Selecionada a partir do híbrido 1031, obtido do cruzamento entre a linhagem IRN 641-70, oriunda do Ensaio Intemacional de Ferrugem do Trigo (International Spring Wheat Rust Nursery, IRN) de 1970, efetuado pelo instituto Biológico, e o cultivar $\mathrm{BH}-1146$.

Linhagem 2: Obtida por seleçāo do híbrido 1475, resultante do cruzamento entre o cultivar LA 1434 (mexicano) e a linhagem Pel 4178-67, introduzida do Instituto de Pesquisa e Experimentação Agropecuária do Sul (IPEAS), RS.

Linhagem 3: Oriunda de seleção do híbrido 254, obtido pelo cruzamento entre os cultivares Sonora-64 (mexicano) e BH-1146.

Linhagem 4: Obtida por seleção do hibrido 1745 , provindo do cruzamento entre os cultivares Sonora-64 e Transfer LR 19, seguido de um retrocruzamento para Sonora-64. 
Linhagem 5: Oriunda por seleção do híbrido 941, resultante do cruzamento entre a linhagem IRN 324-70 e o cultivar IAS-20.

Linhagens 6, 7, 8 e 23: Selecionadas a partir do híbrido 1196, obtido do cruzamento entre o cultivar IAC-5 e a linhagem IRN 33-70.

Linhagens 9, 10 e 11: Obtidas por seleção do hibrido 1235, originário do cruzamento entre 0 cultivar Super $X$ (mexicano) e 0 hibrido entre uma linhagem restauradora de fertilidade $(R)$ proveniente dos EUA e IRN 471-63, seguido de quatro retrocruzamentos para IRN 471-63.

Linhagem 12: Oriunda de seleção do híbrido 963, procedente do cruzamento entre os cultivares Jaral-66 (mexicano) e BH-1146.

Linhagem 13: Resultante da seleção do híbrido 885 , proveniente do cruzamento entre a linhagem IRN 484-70 e o cultivar BH-1146.

Linhagem 14: Selecionada a partir do híbrido 839, obtido do cruzamento entre os cultivares Siete Cerros (mexicano) e C-17.

Linhagem 15: Introduzida do Centro Internacional de Melhoramento de Milho e Trigo (CIMMYT), contém a seguinte genealogia: (Ciano"S" x Sonora-64 Yaqui-50/Tom Thumb - Sonora-64 $\times$ Chris) C-22.

Linhagem 16: Obtida por seleção do hibrido 693, resultante do cruzamento entre o cultivar IAS-51 e a linhagem mexicana IRN 597-70.

Linhagem 17: Oriunda de seleção do híbrido 1399, proveniente do cruzamento entre a linhagem PF 7064, introduzida da Estação Experimental de Passo Fundo, do IPEAS, RS (atuaimente, Centro Nacional de Pesquisa de Trigo, da EMBRAPA) e o cultivar BH-1146.

Linhagem 18: Selecionada a partir do hibrido 425, resultante do cruzamento entre os cultivares IAS-20 e IRN 152-63, seguido de três retrocruzamentos para o 'IAS-20'.

Linhagem 19: Obtida por seleção do híbrido 437, oriundo do cruzamento entre os cultivares IAS-20 e IRN 526-63, seguido de um retrocruzamento para o 'IAS-20'.

Linhagem 20: Selecionada a partir do híbrido 698, proveniente do cruzamento entre os cultivares Noroeste-66 (mexicano) e S-33.

Linhagem 21: Oriunda de seleção do híbrido 722, resultante do cruzamento entre a linhagem IRN 61-70 e o cultivar BH-1146.

Linhagem 22: Introduzida do CIMMYT, México, tem a seguinte genealogia: (Ciano "S" x Sonora-64 - Yaqui-50/Tom Thumb - Sonora-64 x Chris) C-22.

Como controles, foram utilizados os cultivares: $\mathrm{BH}-1146$, de porte alto, suscetivel à ferrugem-do-colmo, ciclo precoce e tolerante à toxicidade de $\mathrm{Al}^{3+}$, e Alondra-S-46, de porte semi-anão, resistente à ferrugem-do-colmo, suscetivel à helmintosporiose e à ferrugem-da-folha e moderadamente sensivel à toxicidade de $\mathrm{Al}^{3+}$. 
A origem dos cultivares utilizados como controle é a seguinte:

BH-1146: Selecionado no Instituto Agronômico de Minas Gerais, Belo Horizonte, é proveniente do cruzamento 'Ponta Grossa l' x 'Fronteira', híbrido que foi cruzado com o cultivar Mentana.

Alondra-S-46: Selecionado pelo CIMMYT, México, e introduzido pelo Centro Nacional de Pesquisa de Trigo, EMBRAPA, onde foi resselecionado.

\subsection{Ensaios conduzidos em condições de campo}

Foi utilizado o delineamento estatistico de blocos ao acaso, com três repetiçōes por local. Cada ensaio foi constituído de 75 parcelas, cada uma formada de cinco linhas de $3 \mathrm{~m}$ de comprimento, espaçadas de 0,20m. Deixou-se uma separação lateral de $0,60 \mathrm{~m}$ entre as parcelas. A semeadura foi feita na base de 80 sementes viáveis por metro de sulco, equivalendo a 1.200 por parcela, conforme recomendação da Comissāo Norte-Brasileira de Pesquisa de Trigo (EMBRAPA, 1983).

Em 1984, foram semeados três ensaios, nos seguintes locais: Centro Experimental de Campinas, Estação Experimental de Capão Bonito e Fazenda Santa Lúcia, município de Cruzália. Em 1985, foram instalados três experimentos, dois nos mesmos locais de 1984 (Capão Bonito e Cruzália) e outro na Estação Experimental de Tiête. Em 1986, foram instalados dois experimentos, um na Estação Experimental de Capão Bonito e outro na Fazenda Boa Esperança, município de Cândido Mota.

Os experimentos de Capāo Bonito foram semeados todos os anos na segunda quinzena de março e, os restantes, na primeira quinzena de abril.

A adubação mineral foi feita a lanço antes da semeadura $e$, posteriormente, incorporada ao solo. As quantidades de fertilizantes aplicadas nos diferentes locais basearam-se nas tabelas de adubaçāo e calagem do Instituto Agronômico (RAlJ et al., 1985).

$\mathrm{Na}$ instalação dos ensaios, retiraram-se amostras compostas dos solos das glebas utilizadas, cujos resultados analíticos se acham no quadro 1 .

Utilizou-se irrigaçāo somente no ensaio efetuado em Campinas, pelo método de aspersão, e coletaram-se os seguintes dados:

Ferrugem-do-colmo e da-folha: Avaliada através de observação geral, em cada parcela, no colmo e nas folhas superiores das plantas, no estádio do início de maturação, em condiçōes naturais de infecção, usando-se a escala modificada de Cobb, empregada para avaliação da resistência no Ensaio Internacional de Ferrugem de Trigo de Primavera (International Spring Wheat Rust Nursery) utilizada por SCHRAM et al. (1974). Essa escala vai de zero a $100 \%$ por área foliar infectada, complementada pelo tipo de reação: $S=$ suscetivel (uredossoro 


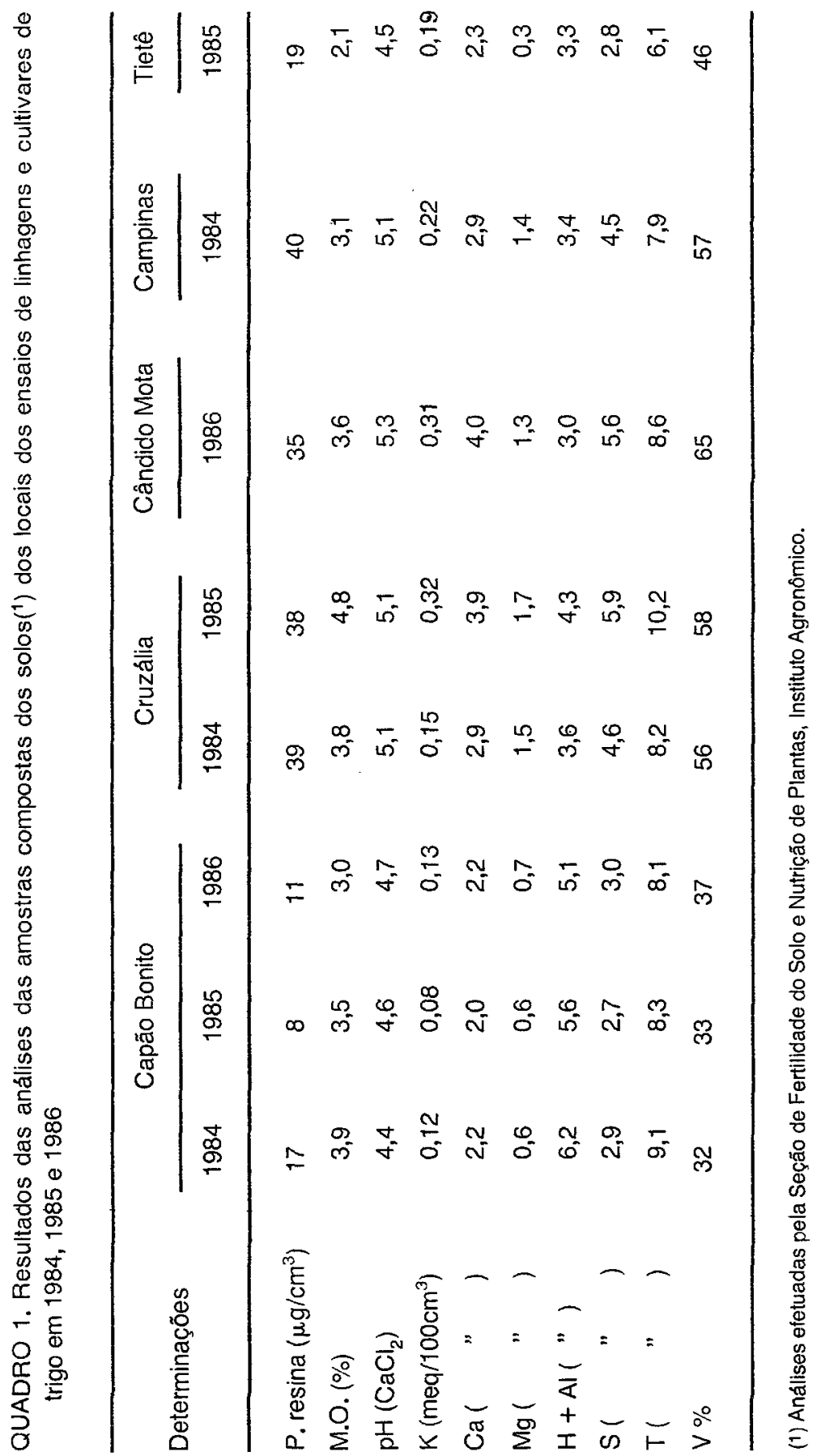


grande, coalescente, sem necrose e sem clorose); $M S=$ moderadamente suscetivel (uredossoro médio); $M=$ intermediária (diversos tipos de reação); $M R=$ moderadamente resistente (uredossoro pequeno); $R=$ resistente (uredossoro minúsculo, rodeado de áreas necróticas).

Doenças da folha: Procedeu-se à avaliação de manchas foliares causadas por Helminthosporium sp. em planta adulta, em condiçōes naturais de infecção, empregando-se uma escala de zero a $99 \%$ de área infectada, apresentada por MEHTA (1978), onde zero é considerado imune; 1 a $5 \%$ resistente; 6 a $25 \%$ moderadamente resistente; 26 a $50 \%$ suscetivel e 51 a $99 \%$ altamente suscetivel.

Oídio: A avaliação de oídio causado pelo fungo Erysiphe graminis sp. tritici foi feita de maneira idêntica à citada para doenças da folha.

Ciclo da emergência ao florescimento: Fazendo-se contagens por parcela do número de dias da emergência das plântulas ao pleno florescimento.

Ciclo da emergência à maturação: Efetuando-se contagens por parcela do número de dias da emergência das plântulas à maturação fisiológica.

Plantas acamadas: Considerando a porcentagem de plantas acamadas em cada parcela, por avaliação visual próxima à época de maturação.

Altura das plantas: Medida no campo, na época de maturação, a distância, em centímetros, do nivel do solo ao ápice da espiga, com exclusão das aristas, e levando-se em consideração a média de diferentes pontos em cada parcela.

Comprimento da espiga: Considerando o comprimento médio, em centímetros, de vinte espigas tomadas ao acaso em cada parcela, excluindo-se as aristas.

Espiguetas: Computando o número médio de espiguetas de vinte espigas tomadas ao acaso em cada parcela.

Grãos por espiga: Considerando o número médio de grãos contados em vinte espigas colhidas ao acaso, em cada parcela.

Grãos por espigueta: Calculando-se pela divisão do número total de grãos de vinte espigas coletadas ao acaso, em cada parcela, pelo número total de suas espiguetas.

Peso de cem grãos: Levando em conta o peso, em gramas, de cem grāos tomados ao acaso na produçāo total de cada parcela.

Produção de grãos: Considerando a produção total de grãos obtida nas cinco linhas de cada parcela.

\subsection{Ensaios em condições de casa de vegetação e laboratório}

\subsubsection{Resistência a raças dos agentes causais da ferrugem-do- -colmo e da-folha.}

As sementes das linhagens e cultivares estudados foram remetidas ao Centro Nacional de Pesquisa de Trigo da EMBRAPA, Passo Fundo (RS) para identificação, quanto à resistência em estádio de plântula, em condiçōes de casa 
de vegetação, a algumas raças de $P$. graminis tritici (G-15, G-17, G-18, G-19, G-20 e G-21) e $P$. recondita (B-26, B-27, B-29 e B-30), de ocorrência comum no Brasil (BARCELLOS, 1985, e COELHO, 1985).

\subsubsection{Tolerância à toxicidade de alumínio}

As linhagens e cultivares foram testados para tolerância a $0,2,4,6,8$ e $10 \mathrm{mg} /$ litro de Al3t em soluções nutritivas, conforme método já publicado (CAMARGO \& OLIVEIRA, 1981, CAMARGO et al., 1980, e MOORE et al., 1976).

\section{RESULTADOS E DISCUSSÃO}

As produções médias de grãos transformadas em quilogramas/hectare, encontram-se no quadro 2. As análises estatísticas individuais dos experimentos mostraram efeitos altamente significativos para linhagens e cultivares em Capão Bonito (1986) e em Cruzália (1984 e 1985); efeitos significativos ao nivel de 5\% em Capão Bonito (1984 e 1985), em Campinas (1984) e em Tietê (1985); e efeitos não-significativos em Cândido Mota (1986).

Nas análises conjuntas dos ensaios conduzidos em vários locais num mesmo ano verificaram-se efeitos altamente significativos para tratamentos, locais e interaçōes tratamentos x locais: eles eram esperados, uma vez que os locais estudádos representam regiōes tritícolas distintas paulistas, caracterizadas por diferentes condiçōes edafoclimáticas.

Considerando a existência de uma interação significativa tratamento $x$ local, decidiu-se estudar o comportamento das linhagens e cultivares dentro de cada local nos diferentes anos.

No ensaio de Capão Bonito, em 1984, verificou-se que a linhagem 19 foi a mais produtiva (2.489kg/ha), diferindo, entretanto, pelo teste de Tukey ao nivel de $5 \%$, apenas da linhagem $4(944 \mathrm{~kg} / \mathrm{ha})$. Em 1985, destacaram-se as linhagens 5 e 19, as quais não diferiram, porém, estatisticamente, dos demais tratamentos; e em 1986, a linhagem 19 foi a mais produtiva $(2.275 \mathrm{~kg} / \mathrm{ha})$, diferindo das linhagens $1,3,4,5,9,10,11,16,17,20,22$ e 23 e do cultivar Alondra-S-46.

$\mathrm{Na}$ análise conjunta dos ensaios plantados em Capão Bonito, verificaram-se efeitos altamente significativos para anos, tratamentos e interação tratamentos $x$ anos.

Apesar da interação significativa tratamentos $x$ anos, a linhagem 19 apresentou boa estabilidade em relação à produção de grãos. Na média dos três experimentos de Capão Bonito, ela produziu $2.466 \mathrm{~kg} / \mathrm{ha}$, diferindo do cultivar Alondra-S-46, com 1.396kg/ha, porém não do 'BH-1146', com $2.097 \mathrm{~kg} / \mathrm{ha}$. 


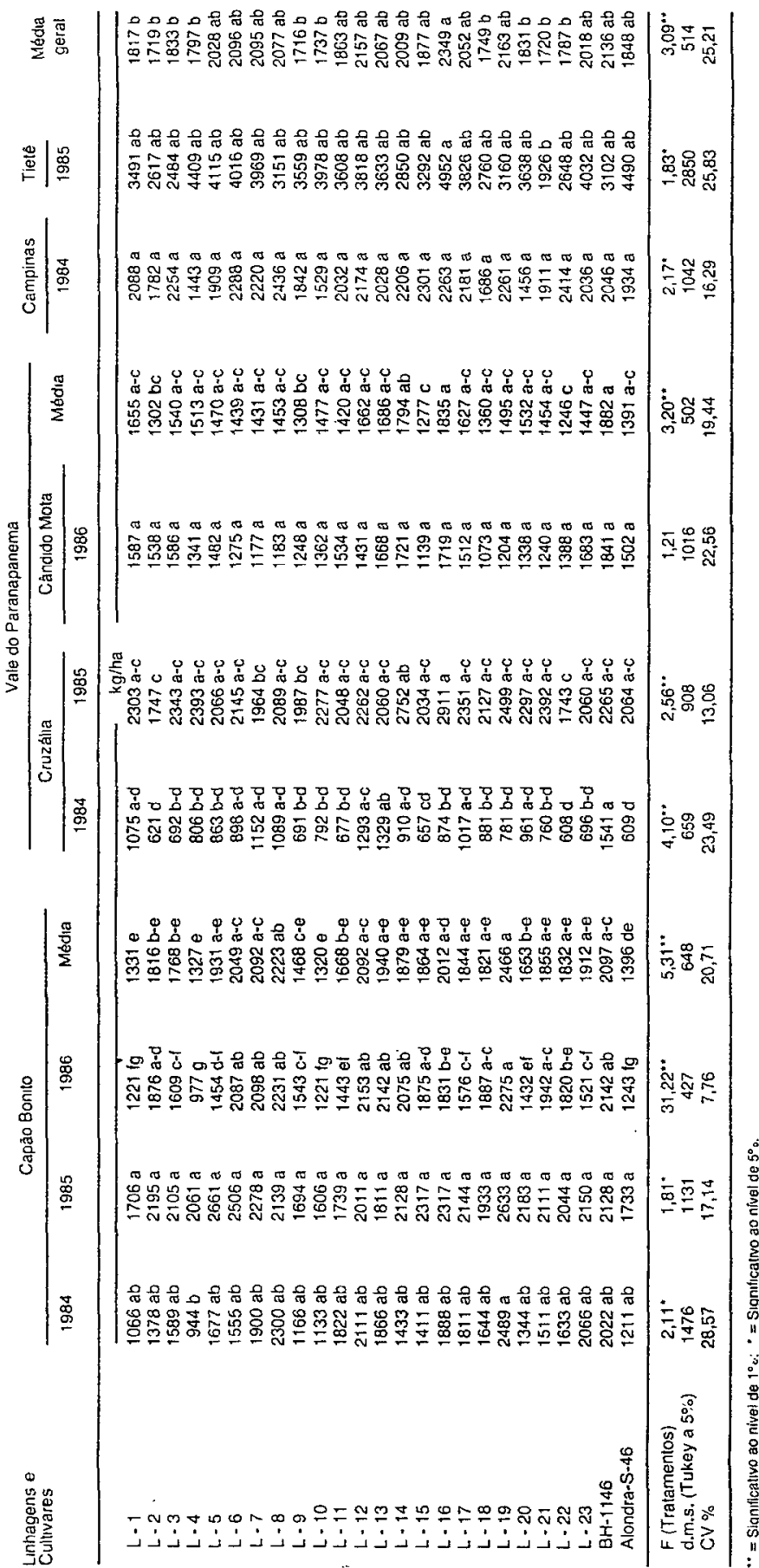


No ensaio plantado em Cruzália, em 1984, o cultivar $\mathrm{BH}-1146$ foi o mais produtivo $(1.541 \mathrm{~kg} / \mathrm{ha})$, diferindo das linhagens $2,3,4,5,9,10,11,15,16,18,19$, 21, 22 e 23 e do cultivar Alondra-S-46. Nesse ano, houve ocorrência de seca durante o ciclo da cultura; nessas condições, o cultivar $\mathrm{BH}-1146$ mostrou grande adaptação, pelo ciclo precoce, tolerância ao $\mathrm{Al}^{3+}$ presente no subsolo e à seca, aliada à não-ocorrência de ferrugem-do-colmo, à qual é altamente suscetível, confirmando resultados obtidos por CAMARGO (1972). No ensaio de 1985, que foi um ano de condiçōes climáticas altamente favoráveis à cultura do trigo, destacou-se quanto à produtividade a linhagem $16(2.911 \mathrm{~kg} / \mathrm{ha})$, diferindo apenas das linhagens 2, 7, 9 e 22. No ensaio instalado em 1986, em Cândido Mota, não se observaram diferenças significativas entre os tratamentos. Considerando em conjunto os experimentos do Vale do Paranapanema, o cultivar BH-1146 e a linhagem 16 exibiram maior produção de grãos (1.882 e $1.835 \mathrm{~kg} /$ ha respectivamente), diferindo significativamente apenas das linhagens $2,9,15$ e 22 , porém não do cultivar Alondra-S-46.

No ensaio de Campinas, não houve diferenças significativas entre os tratamentos, porém a linhagem $8(2.436 \mathrm{~kg} / \mathrm{ha})$ foi a mais produtiva.

A linhagem 16 destacou-se quanto à produção de grãos $(4.952 \mathrm{~kg} / \mathrm{ha})$ no experimento instalado em Tietê, em 1985, diferindo, porém, ao nivel de $5 \%$, somente da linhagem 21 (1.926kg/ha).

No quadro 3, encontram-se os graus de infecção de ferrugem-do-colmo e da-folha, oídio e helmintosporiose, em condição de campo, alcançados pelos cultivares e linhagens, nos três anos. No quadro 4, as reações das linhagens e cultivares (estádio de plântula) a Puccinia graminis f. $\mathrm{sp}$. tritici e P. recondita em condição de casa de vegetação.

Nos anos considerados, não ocorreram condições naturais favoráveis para infecção do agente causal da ferrugem-do-colmo. O cultivar $\mathrm{BH}-1146$, bastante suscetivel a essa doença, apresentou um grau máximo de infecção de $10 S$ apenas no ensaio instalado em Campinas em 1984. As linhagens 9,10 e 11 e o cultivar Alondra-S-46 mostraram-se resistentes e as linhagens 14, 18, 19 e 21 e o cultivar $\mathrm{BH}-1146$, suscetíveis, às seis raças do agente causal da ferrugem-do-colmo testadas em condição de casa de vegetação.

Em relação à ferrugem-da-folha, todos os genótipos se apresentaram sensíveis a pelo menos uma das quatro raças em casa de vegetação; quanto à resistência em planta adulta em condição de campo, porém, destacaram-se as linhagens 11, 16 e 18 e o cultivar $\mathrm{BH}-1146$, com graus máximos de infecção inferiores ou iguais a 15S. Nessa mesma situação, o cultivar Alondra-S-46 mostrou-se suscetivel à ferrugem-da-folha, com um grau máximo de infecção de $40 \mathrm{~S}$.

Em relação ao oídio, destacaram-se, quanto à resistência em planta adulta, em Capão Bonito e Cruzália, as linhagens 1, 2, 4, 12, 14, 17, 18, 19 e20, com graus de infecção iguais a 10 . Nessas mesmas condições naturais de infecção, as linhagens 8 e 10 apresentaram 40 como grau máximo de infecção. 
MELHORAMENTO DO TRIGO: XXI. AVALIAÇĀO DE LINHAGENS,..

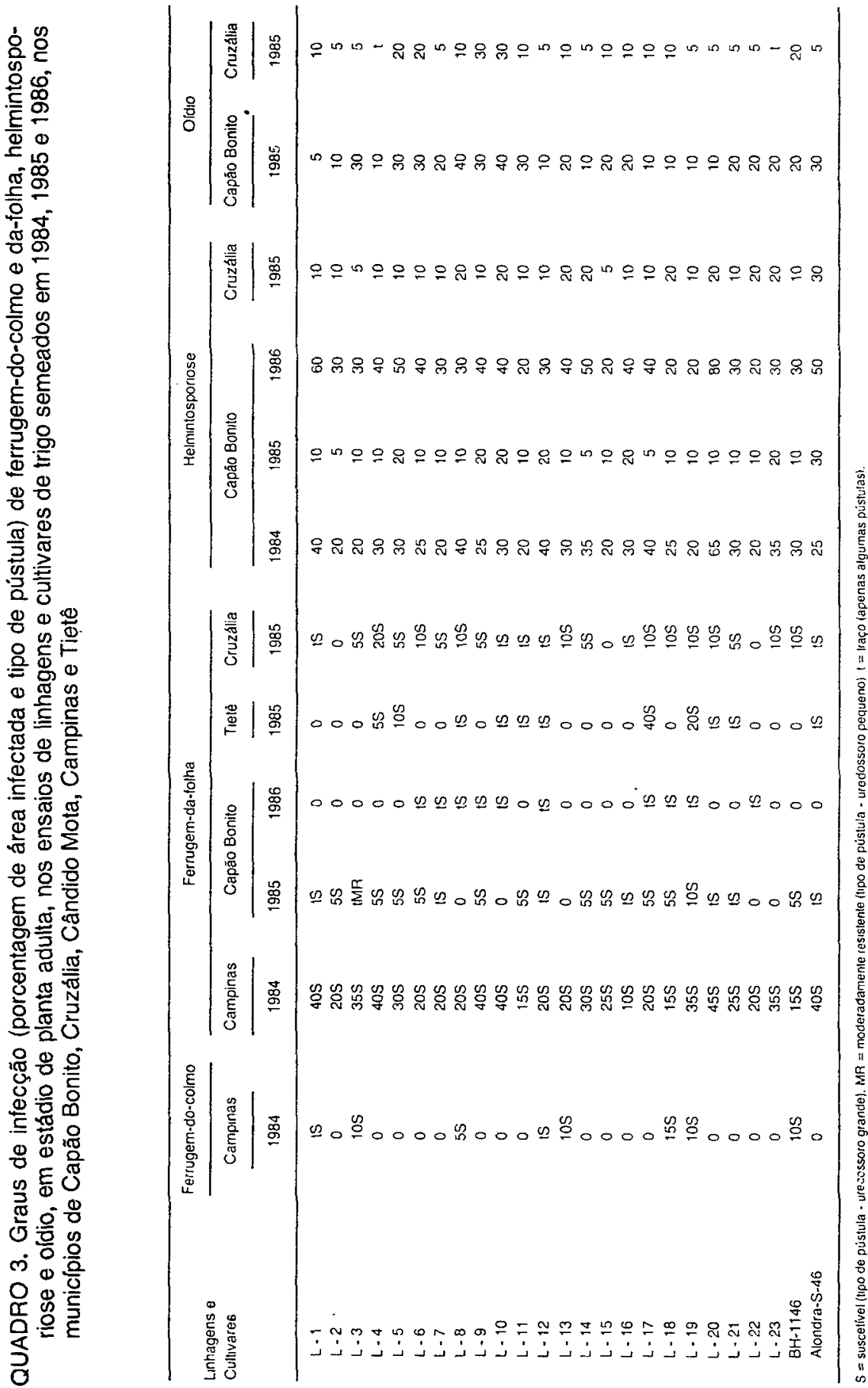




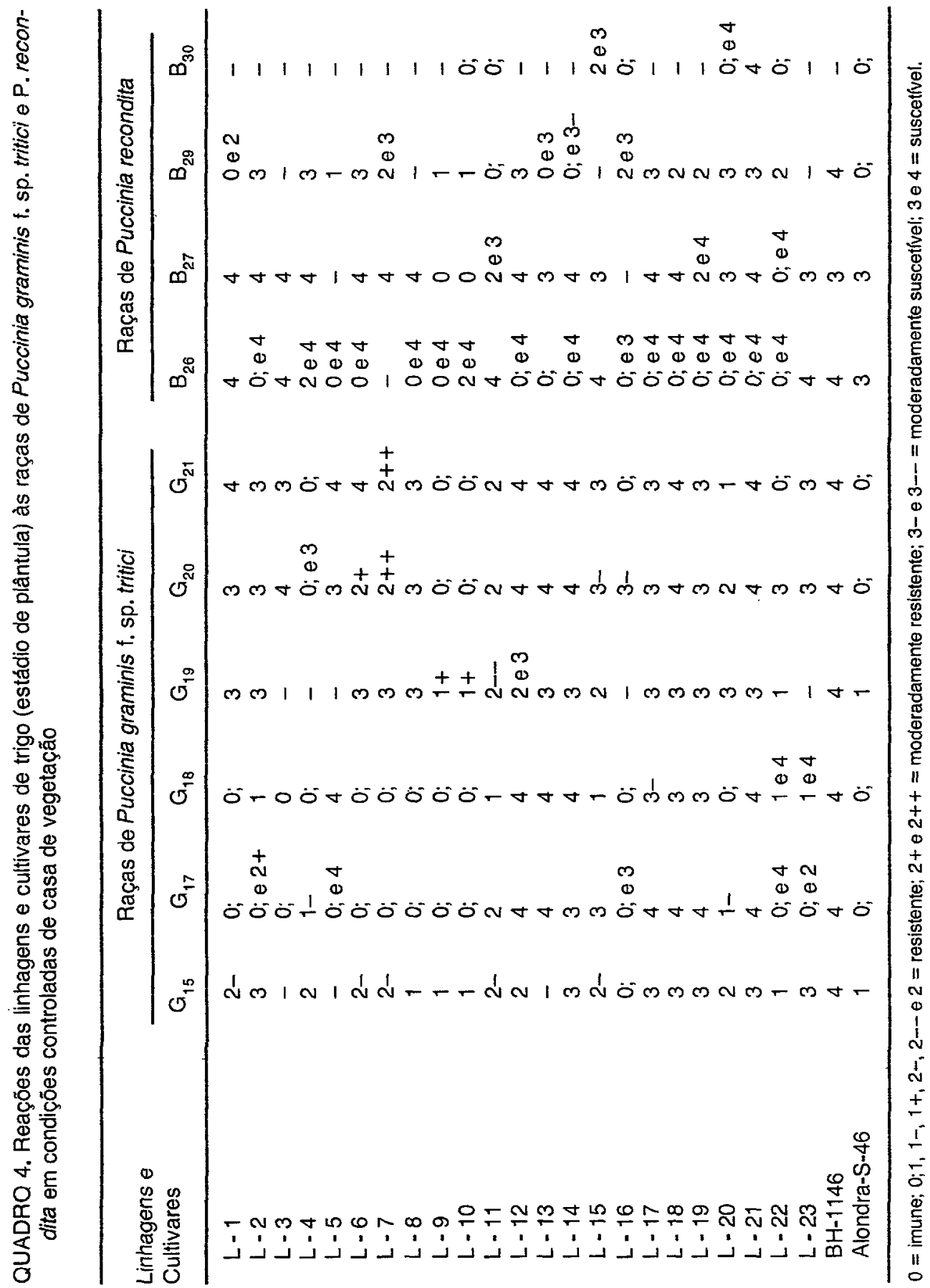


A ocorrência de helmintosporiose tem sido bastante acentuada em Capão Bonito, onde a maioria das linhagens mostrou sintomas da doença: as linhagens 20 e 1 foram as mais suscetiveis, enquanto as linhagens $11,15,18,19$ e 22 exibiram moderada resistência a seu agente causal.

O ciclo e outras caracteristicas agronômicas das linhagens e cultivares estudados encontram-se no quadro 5 . Todas as linhagens foram tão precoces quanto o cultivar $\mathrm{BH}-1146$, com exceção da 11,15 e 22 e do cultivar Alondra-S-46, que exibiram um ciclo médio, levando-se em consideração o ciclo da emergência à maturação.

As linhagens $1,3,9,10,11,15,16,22$ e 23 e o cultivar Alondra-S-46 mostraram plantas significativamente mais baixas que a do cultivar $\mathrm{BH}-1146$. Considerando-se que também apresentaram menor porcentagem de plantas acamadas, esses genótipos estariam entre aqueles com potencial de cultivo em condiçōes de irrigação. $\mathrm{O}$ ' $\mathrm{BH}-1146$ ' e as linhagens 12 e 17 exibiram porte alto $\mathrm{e}$ $40 \%$ de plantas acamadas, nāo sendo indicados para coṇdições irrigadas: suas produçōes poderiam ser prejudicadas pelo acamamento precoce que provocaria a formação de grãos de baixa qualidade e de baixo peso hectolítrico.

A linhagem 7 apresentou as espigas mais compridas, diferindo do cultivar $\mathrm{BH}-1146$, porém não do 'Alondra-S-46'.

O cultivar $\mathrm{BH}-1146$ apresentou o menor número de grãos por espiga, diferindo significativamente das linhagens $6,15,22$ e 23 .

A linhagem 2 mostrou o maior número de grãos por espigueta, isto é, maior fertilidade da espiga, diferindo significativamente das linhagens $7,8,9,12$, 14 e 18 e do cultivar $\mathrm{BH}-1146$.

As linhagens 7 e 8 mostraram maior número de espiguetas por espiga, não diferindo entre si, mas sim dos demais tratamentos, com exceção das linhagens $3,6,15,21$ e 22 .

A linhagem 21 exibiu os grãos mais pesados, diferindo significativamente das linhagens $3,5,11,15,16,18$ e 22.

Os resultados referentes ao teste de tolerância à toxicidade de $\mathrm{Al}^{3+}$ encontram-se no quadro 6.

Considerando $2 \mathrm{mg} /$ litro de $\mathrm{Al}^{3+}$, a linhagem 4 foi sensivel e, as demais, tolerantes. As linhagens 6 e 7 foram toierantes a $2 \mathrm{mg} /$ litro de $\mathrm{Al}^{3+}$ na solução tratamento, porém exibiram sensibilidade quando se empregaram soluçōes com $4 \mathrm{mg} /$ litro de $\mathrm{Al}^{3+}$, sendo, portanto, classificadas como moderadamente sensiveis.

As linhagens 8,11 e 20 foram tolerantes a $4 \mathrm{mg} /$ litro de $\mathrm{Al}^{3+}$, porém demonstraram sensibilidade à presença de $6 \mathrm{mg} /$ /itro de $\mathrm{Al}^{3+}$ nas soluções de tratamento, sendo classificadas como moderadamente tolerantes. 


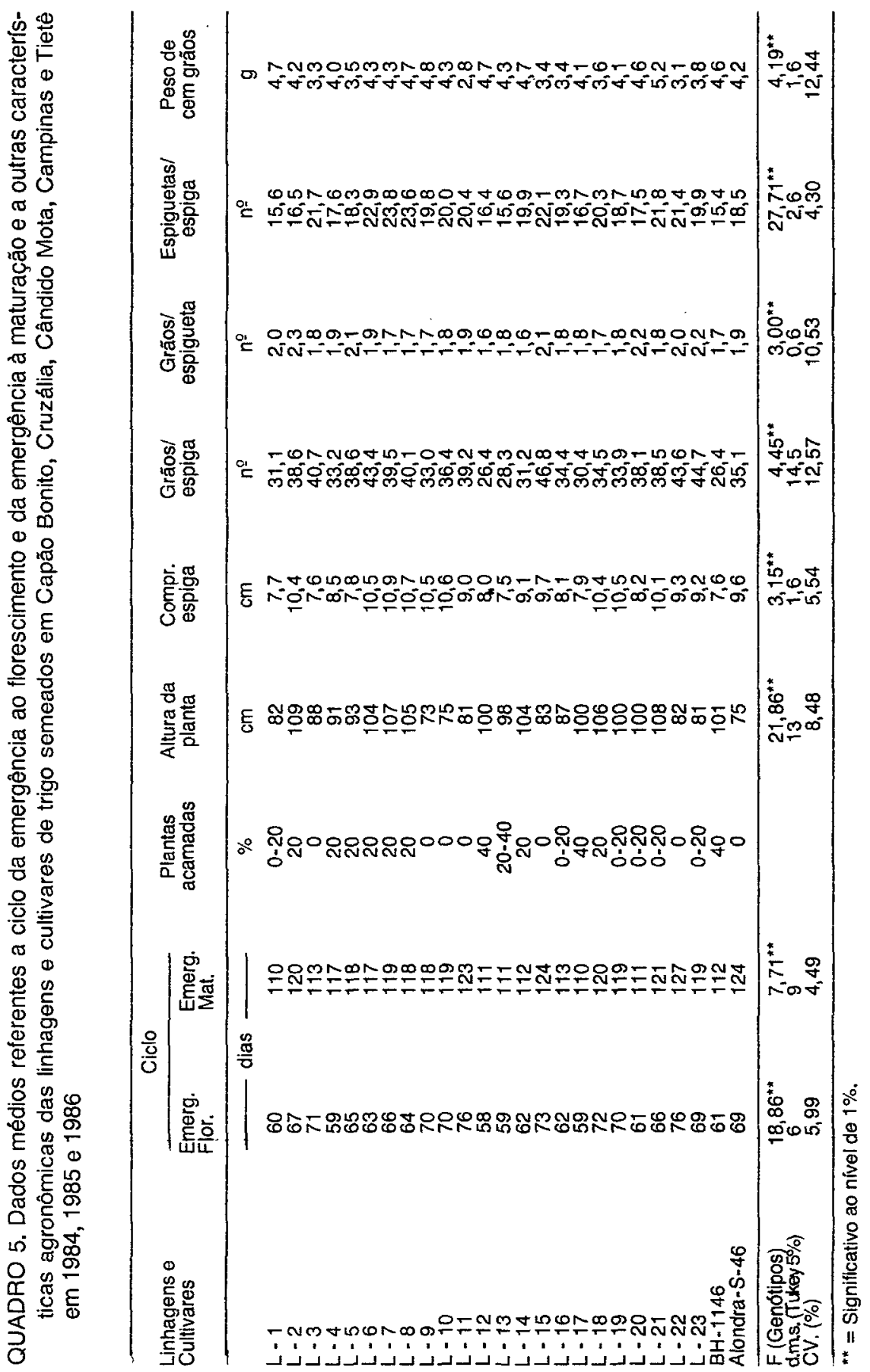


QUADRO 6. Comprimento médio das raízes das linhagens e cultivares de trigo, medido após 72 horas de crescimento na solução nutritiva completa, que se seguiu de crescimento na solução de tratamento contendo seis concentraçōes de $\mathrm{Al}^{3+}$

Cultivares e

Linhagens
Concentraçāo de alumínio (mg/itro)

\begin{tabular}{llllll}
\hline 0 & 2 & 4 & 6 & 8 & 10
\end{tabular}

$L-1$

$L-2$

$L-3$

$L-4$

'L- 5

$L-6$

$L-7$

$L-8$

L-9

$L-10$

$L-11$

$L-12$

$L-13$

$L-14$

$L-15$

$L-16$

$L-17$

L - 18

$L-19$

L - 20

L - 21

L- 22

$L-23$

$\mathrm{BH}-1146$

Alondra-S-46

\begin{tabular}{rrrrrr}
\hline 63,4 & 57,9 & 40,0 & 21,4 & 10,4 & 2,5 \\
73,1 & 77,2 & 24,2 & 15,1 & 3,6 & 0,0 \\
79,2 & 50,4 & 39,9 & 13,1 & 17,1 & 5,2 \\
63,4 & 0,0 & 0,0 & 0,0 & 0,0 & 0,0 \\
63,3 & 45,9 & 38,4 & 36,0 & 26,9 & 23,4 \\
49,7 & 0,6 & 0,0 & 0,0 & 0,0 & 0,0 \\
43,6 & 9,3 & 0,0 & 0,0 & 0,0 & 0,0 \\
60,9 & 9,3 & 1,1 & 0,0 & 0,0 & 0,0 \\
61,8 & 34,1 & 2,9 & 0,9 & 0,0 & 0,0 \\
83,4 & 24,7 & 2,3 & 0,6 & 0,0 & 0,0 \\
74,6 & 36,6 & 3,3 & 0,0 & 0,0 & 0,0 \\
64,0 & 57,9 & 30,7 & 0,6 & 2,9 & 1,5 \\
96,2 & 67,8 & 49,1 & 39,7 & 28,6 & 28,1 \\
55,4 & 58,1 & 43,1 & 31,0 & 17,6 & 17,6 \\
44,1 & 30,6 & 8,8 & 0,3 & 0,0 & 0,0 \\
60,4 & 41,5 & 2,6 & 3,0 & 0,2 & 0,3 \\
73,5 & 49,8 & 42,6 & 34,2 & 21,9 & 22,9 \\
63,4 & 65,1 & 47,6 & 40,6 & 29,5 & 15,4 \\
70,3 & 45,8 & 33,4 & 20,6 & 3,2 & 0,4 \\
60,8 & 53,2 & 21,7 & 0,0 & 0,0 & 0,0 \\
66,7 & 60,2 & 52,3 & 39,3 & 30,3 & 27,6 \\
52,5 & 39,6 & 8,6 & 0,8 & 2,3 & 0,0 \\
58,0 & 44,6 & 12,5 & 2,7 & 2,6 & 0,0 \\
60,4 & 60,7 & 48,1 & 35,4 & 24,4 & 19,3 \\
62,5 & 48,6 & 2,4 & 2,8 & 0,0 & 0,0 \\
& & & & & \\
\hline
\end{tabular}


As linhagens 9,10 e 15 e o cultivar Alondra-S-46 foram sensiveis a $8 \mathrm{mg} /$ litro de $\mathrm{Al}^{3+}$ nas soluções de tratamento, porém apresentaram-se como tolerantes na presença de $6 \mathrm{mg} / \mathrm{litro}$ de $\mathrm{Al}^{3+}$, sendo, portanto, classificadas como tolerantes à toxicidade de $\mathrm{Al}^{3+}$.

O cultivar BH-1146 e as linhagens 1, 3, 5, 12, 13, 14, 16, 17, 18, 19 e 21 mostraram-se tolerantes mesmo quando se adicionaram $10 \mathrm{mg} / \mathrm{litro}$ de $\mathrm{Al}^{3+}$ nas soluçōes de tratamento, sendo os genótipos classificados como muito tolerantes à toxicidade de $\mathrm{Al}^{3+}$.

A linhagem 19 mostrou grande potencial de cultivo na região Sul do Estado de São Paulo, dada a sua boa adaptação às condições de solo ácido de Capão Bonito ( $\mathrm{V} \%$ variando de 32 a 37 ), pela sua grande tolerância à toxicidade de $\mathrm{Al}^{3+}$ (Quadro 6). Apresentou ciclo precoce e porte alto semelhante ao cultivar $\mathrm{BH}-1146$, porém menor porcentagem de plantas acamadas e espigas mais compridas. Essa linhagem se mostrou moderadamente resistente à helmintosporiose, doença de difícil controle por meio de resistência genética, e de grande importância para a região, em vista das condiçōes climáticas favoráveis (chuvas freqüentes e elevada umidade relativa) e ao grande potencial de inóculo no solo devido ao grande número de anos de cultivo de trigo na regiāo (Quadros 3 e 5). A linhagem 19 mostrou-se ainda de moderada resistência ao oídio, porém de suscetibilidade às ferrugens-do-colmo e da-folha em condiçōes de campo e de casa de vegetação, como o cultivar BH-1146; necessita, portanto, de incorporação de genes para resistência a essas ferrugens por meio de cruzamentos. A curto prazo, poderia ser cultivada com a aplicação de fungicidas para o controle das ferrugens nos anos favoráveis ao seu estabelecimento.

A obtenção da linhagem 16 permitiu combinar, com êxito, num único germoplasma, boa produtividade aliada ao porte baixo proveniente do genitor IRN $597-70$ e à tolerância à toxicidade de $\mathrm{Al}^{3+}$, oriunda do genitor IAS-51, confirmando trabalhos de CAMARGO et al. (1980) e CAMARGO (1984), que mostraram que a tolerância ao $\mathrm{Al}^{3+}$ não foi associada com altura e produção de grãos. Os resultados obtidos no presente trabalho permitiram demonstrar que 0 fator genético para tolerância ao $\mathrm{Al}^{3+}$ presente na linhagem 16 nāo limitou a produção de grãos em solos do Vale do Paranapanema e de Tietê, onde houve ocorrência de menor acidez. Esses resultados discordam dos obtidos por PRIOLI (1987) que mostrou, em milho, uma associação entre baixa produtividade e tolerância ao $\mathrm{Al}^{3+}$ quando os híbridos foram cultivados em solos de baixa acidez. A linhagem 16, além da menor relação palha: grão do que o cultivar BH-1146, apresentou também menor suscetibilidade ao acamamento. Exibiu resistência a três raças de ferrugem-do-colmo em casa de vegetação, ao passo que o cultivar $\mathrm{BH}-1146$ foi altamente suscetivel para as seis raças testadas. Apesar de mostrar-se resistente a somente uma das raças testadas de ferrugem-da-folha em casa de vegetação, a linhagem 16 apresentou-se como um dos genótipos mais resistentes a essa doença em condição de campo. Exibiu suscetibilidade à 
helmintosporiose em Capão Bonito, porém essa doença normalmente não é muito importante no Vale do Paranapanema devido à freqüente deficiência de chuvas, principalmente após o florescimento do trigo, época crítica para o desenvolvimento da doença. Esse germoplasma mostrou-se com grande potencial de ser cultivado em condição de sequeiro no Vale do Paranapanema.

As avaliaçōes do presente trabalho também permitiram a identificaçāo de germoplasmas de valor para utilizar em cruzamentos, como fontes genéticas de características agronômicas de interesse do programa de melhoramento do Instituto Agronômico. Entre eles, podem-se destacar as linhagens 9, 10 e 11 e o cultivar Alondra-S-46, com resistência às raças prevalecentes de ferrugem-docolmo; as linhagens 1,3 e 16 de ciclo precoce, porte baixo e tolerantes à toxicidade de $\mathrm{Al}^{3+}$; a linhagem 7 , com espigas compridas e maior número de espiguetas por espiga; a 2, com grande fertilidade nas espigas, e a 21, com grãos mais pesados.

\section{AGRADECIMENTO}

Os autores agradecem ao Centro Nacional de Pesquisa de Trigo, EMBRAPA,os teste de resistência às ferrugens-do-colmo e da-folha em casa de vegetação.

\section{SUMMARY \\ WHEAT BREEDING. \\ $X X I$. EVALUATION OF INBRED LINES IN DIFFERENT REGIONS OF THE STATE OF SÄO PAULO, BRAZIL}

Twenty three inbred lines obtained at the Instituto Agronômico from the wheat breeding program plus the cultivars $\mathrm{BH}-1146$ and Alondra-S-46 were evaluated in field experiments carried out at Campinas Experiment Center, Capão Bonito and Tietê Experiment Stations, and at two farms located in the Paranapanema Valley, during the period 1984-86. Grain yield, plant height, number of days from emergence to flowering and from emergence to maturation, percentage of lodged plants, head lenght, number of grain per spike and per spikelet, number of spikelets per spike, weight of 100 grains, and resistance to stem and leaf rusts were evaluated under field conditions. The resistance to stem and leaf rusts was tested in the greenhouse, and tolerance to aluminum toxicity was tested in the laboratory. Considering the experiments carried out at Capão Bonito the line 19 presented good productivity showing moderate resistance to Helminthosporium $\mathrm{sp}$. and high tolerance to aluminum toxicity. This line was early in maturity and exhibited tall type of plant but it was resistant to lodging. The cultivar $\mathrm{BH}-1146$ and the line 16 showed high grain yield at the Paranapanema Valley. The line 16 presented a semidwarf type, early maturity, field resistance to leaf rust, resistance to lodging and tolerance to Al toxicity. At Tietê the line 16 showed high productivity. There were no differences among the 
lines at Campinas. The lines $1,3,9,10,11,15,16,22,23$ and the cultivar Alondra-S.46 exhibited semidwarf type when compared to the tall cultivar $\mathrm{BH}-1146$. The lines 9,10,11 and the cultivar Alondra-S-46 were resistant to stem rust, presenting at seedling stage, resistance to six races under greenhouse conditions. The lines $11,16,18$ and the cultivar $\mathrm{BH}-1146$ presented low levvels of the leaf rust from natural infection out in the field. The line 7 with long heads, the lines 7 and 8 with large number of spikelets per spike, the line 2 presenting high head fertility and the line 21 exhibiting heavy grains were considered as good genetic sources of these characteristics for the wheat breeding program. The lines $1,3,5,12,13,14,16,17,18,19,21$ and the cultivar $\mathrm{BH}-1146$ were tolerant to the presence of $10 \mathrm{mg} /$ iter of $\mathrm{Al}$ in the nutrient solution.

Index terms: plant breeding; wheat; yield; stem and leaf rusts; aluminum toxicity.

\section{REFERÊNCIAS BIBLIOGRÁFICAS}

ALCOVER, M. Melhoramento de variedades de trigo em São Paulo. Campinas, Coordenadoria de Assistência Técnica Integral, 1971. 26p.

. Resultados experimentais com trigo na Estação Experimental de Capão Bonito do Instituto Agronômico de Campinas, Estado de São Paulo. In: REUNIĀO ANUAL DE PESQUISA DE TRIGO, 1., Pelotas, 1969. Pelotas, Instituto de Pesquisa e Experimentação Agropecuária do Sul. 10p. (Mimeografado)

BARCELLOS, A.L. Ferrugem da folha de trigo - populaçāo patogênica no Brasil em $1983 \mathrm{e}$ 1984, e reaçōes dos cultivares dos ensaios finais da Regiāo Centro-Sul. In: REUNIĀO DA COMISSÃO GENTRO-SUL BRASILEIRA DE PESQUISA DE TRIGO, 1., Londrina, 1985. Passo Fundo, EMBRAPA, Centro Nacional de Pesquisa de Trigo, 1985. p.1-38.

CAMARGO, C.E.O. Estudo de variedades de trigo para o Estado de São Paulo. Piracicaba, ESALQ, 1972. 102+34p. Tese (Doutoramento)

. Melhoramento genético do trigo para irrigação de inverno nas condiçōes do Estado de São Paulo. In: SIMPÓSIO SOBRE O MANEJO DE ÁGUA NA AGRICULTURA, Campinas, 1987. Campinas, Fundação Cargill, 1987. p.134-174.

. Melhoramento do trigo. $X$. Estimativas da herdabilidade e correlaçōes entre tolerância à toxicidade de alumínio e produção de grãos com outros caracteres agronômicos em trigo. Bragantia, Campinas, 43(2):615-628, 1984.

; ALCOVER, M. \& ISSA, E. Comportamento de cultivares de trigo em condições de sequeiro no Estado de São Paulo. Bragantia, Campinas, 33:43-53, 1974.

; KRONSTAD, W.E. \& METZGER, R.J. Parent-progeny regression estimates and associations of height levels with aluminum toxicity and grain yield in wheat. Crop Science, 20:355-358, 1980.

\& OLIVEIRA, O.F. Tolerância de cultivares de trigo a diferentes níveis de aluminio em solução nutritiva e no solo. Bragantia, Campinas, 40:21-31, 1981.

COELHO, E.T. Informaçōes sobre ferrugem do colmo do trigo (Puccinia graminis tritici). In: REUNIÄO DA COMISSÃO CENTRO-SUL BRASILEIRA DE PESQUISA DE TRIGO, 1., Londrina, 1985. Passo Fundo, EMBRAPA, Centro Nacional de Pesquisa de Trigo, 1985. p.1-5. 
EMBRAPA. Centro de Pesquisa Agropecuária dos Cerrados. Ata da IX Reunião da Comissão Norte-Brasileira de Pesquisa de Trigo, Brasilia, 1983. 71p.

FELÍCIO, J.C.; BARROS, B.C.; CAMARGO, C.E.O. \& BAR, W.H. Maracai (IAC-17) e Xavantes (IAC-18): cultivares de trigo para o Estado de São Paulo. Bragantia, Campinas, 42:15-25, 1983.

; CAMARGO, C.E.O. \& BARROS, B.C. Estudo comparativo de trigo em Latossolo-Roxo, no Estado de São Paulo. Bragantia, Campinas, 35:147-154, 1976.

\& VITTI, P. Iguaçu (IAC-21) e Araguaia (IAC-22). Cultivares de trigo de sequeiro para o Estado de São Paulo. Bragantia, Campinas, 44(1):115-128, 1985.

MEHTA, Y.R. Doenças do trigo e seu controle. São Paulo, Ceres, 1978. 190p.

MOORE, D.P.; KRONSTAD, W.E. \& METZGER, R.J. Screening wheat for aluminum tolerance. In: WORKSHOP ON PLANT ADAPTATIONS TO MINERAL STRESS IN PROBLEM SOILS, Beltsville, Maryland, 1976. Proceedings. p.287-295.

PRIOLI, A.J. Análise genética da tolerância à toxidez do aluminio em milho (Zea mays L.). Campinas, UNICAMP, Instituto de Biologia, 1987. 182p. Tese (Doutoramento)

RAIJ, B. van; SILVA, N.M.; BATAGLIA, O.C.; QUAGGIO, J.A.; HIROCE, R.; CANTARELLA, H.; BELINAZZI JUNIOR, R.; DECHEN, A.R. \& TRANI, P.E. Recomendaçōes de adubação e calagem para o Estado de São Paulo. Campinas, Instituto Agronômico, 1985. 107p. (Boletim técnico, 100)

SÄO PAULO. Secretaria de Agricultura e Abastecimento. Relatórios do Acordo entre a $S A A$, através do Instituto Agronômico, e as Cooperativas Rurais do Vale do Paranapanema. Campinas, 1985 e 1986.

SCHRAM, W.; FULCO, W.S.; SOARES, M.H.G. \& ALMEIDA, A.M.P. Resistência de cultivares de trigo em experimentaçāo ou cultivo no Rio Grande do Sul às principais doenças fúngicas. Agronomia Sulriograndense, Porto Alegre, 10:31-39, 1974. 